Supporting Information for:

\title{
Convenient Synthesis of Bicyclic Malonamides: A new class of conformationally preorganized ligands for f-block ion binding.
}

Bevin W. Parks, Robert D. Gilbertson, Dylan W. Domaille, and James E. Hutchison

\section{SUPPORTING INFORMATION TABLE OF CONTENTS}

Synthesis of alcohol 13

S2

Synthesis of benzyl-protected amines 19

Table of yields

Alkyl amines

Perfluoro-amines

Synthetic attempts towards the acid-functionalized BMA

Benzyl ester benzyl-protected amine

${ }^{1} \mathrm{H}$ NMR of ester-amine intermediate 6

Ethyl ester BMA intermediate

Spectroscopic Analysis of BMA structure

${ }^{1} \mathrm{H}$ NMR Spectra of $\mathbf{1 b}$ in $\mathrm{CDCl}_{3}$ and $\mathrm{D}_{2} \mathrm{O}$

${ }^{1} \mathrm{H}$ NMR spectrum of methyne c

Deuterium exchange

Splitting tree

${ }^{1} \mathrm{H}$ NMR spectra for purity

$1 \mathrm{e}$

1f in $\mathrm{CDCl}_{3}$

1f in $\mathrm{D}_{2} \mathrm{O}$

$1 g$
S3

S3

S5

S7

S8

S9

S11

S13

S14

S15

S16

S17

S18

S19 


\section{Synthesis of Alcohol 13.}

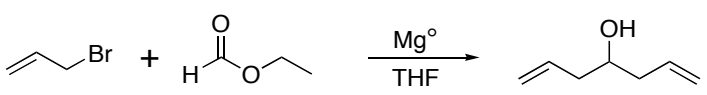

1,6-Heptadiene-4-ol (13). A flask was charged with Mg turnings (41.0 g, 1.69 mol) and THF under a $\mathrm{N}_{2}$ atmosphere. A few drops of allyl bromide were added to the THF and the solvent was heated to initiate the formation of allylmagnesium bromide. Once the reaction had started, a mixture of allyl bromide (200 g, $1.65 \mathrm{~mol})$ and ethyl formate (60.0 g, $0.81 \mathrm{~mol})$ in THF was added dropwise at a rate fast enough to maintain autoreflux of the reaction mixture. The reaction was heated to maintain reflux for $2 \mathrm{~h}$ after the addition was completed, then cooled to $0{ }^{\circ} \mathrm{C}$ and $10 \% \mathrm{HCl}$ was carefully added until the aqueous phase was acidic to litmus paper. The layers were separated and the aqueous layer was extracted with ether $(2 \times 100 \mathrm{~mL})$. The organics were combined and washed with water $(100 \mathrm{~mL})$, saturated aqueous $\mathrm{NaHCO}_{3}(100 \mathrm{~mL})$, and brine $(100 \mathrm{~mL})$, then dried $\left(\mathrm{MgSO}_{4}\right)$, and filtered through Celite. Removal of solvents by rotary evaporation gave a yellow oil that was purified by distillation at atmospheric pressure (bp $\left.150-151{ }^{\circ} \mathrm{C}\right)$ to yield $\mathbf{1 3}$ as a colorless oil $(87.2 \mathrm{~g}, 0.78 \mathrm{~mol}, 96 \%) .{ }^{1} \mathrm{H} \mathrm{NMR}\left(\mathrm{CDCl}_{3}\right) \delta$ $5.837(\mathrm{~m}, 2 \mathrm{H}), 5.156(\mathrm{~m}, 2 \mathrm{H}), 5.112$ (triplet, $J=0.9 \mathrm{~Hz}, 2 \mathrm{H}), 3.711\left(\mathrm{tt}, J_{1}=5.1 \mathrm{~Hz}, \mathrm{~J}_{2}=\right.$ 7.5 Hz, 1H), 2.14-2.34 (m, 4H). Anal. Calcd for $\mathrm{C}_{7} \mathrm{H}_{12} \mathrm{O}: \mathrm{C}, 74.95 ; \mathrm{H}, 10.78$. Found: $\mathrm{C}$, $74.83 ; \mathrm{H}, 11.02$. 
PROCEDURES FOR SYNTHESES OF BENZYL-PROTECTED AMINES (19).

Table S1. Yields for benzyl protected amines.

\begin{tabular}{cccc}
\hline entry & product & $\mathrm{R}=$ & $\%$ yield \\
\hline 1 & $\mathbf{1 9 a}$ & $\left(\mathrm{CH}_{2}\right)_{7} \mathrm{CH}_{3}$ & $85^{a}$ \\
2 & $\mathbf{1 9 b}$ & $\mathrm{CH}_{3}$ & $-{ }^{b}$ \\
3 & $\mathbf{1 9 c}$ & $\left(\mathrm{CH}_{2}\right)_{9} \mathrm{CH}_{3}$ & $98^{a}$ \\
4 & $\mathbf{1 9 d}$ & $\left(\mathrm{CH}_{2}\right)_{15} \mathrm{CH}_{3}$ & $74^{a}$ \\
5 & $\mathbf{1 9 e}$ & $\left(\mathrm{CH}_{2}\right)_{2} \mathrm{Ph}$ & $-{ }^{b}$ \\
6 & $\mathbf{1 9 f}$ & $\left(\mathrm{CH}_{2}\right)_{2} \mathrm{OH}$ & $-{ }^{b}$ \\
7 & $\mathbf{1 9 g}$ & $\left(\mathrm{CH}_{2}\right)_{4} \mathrm{OH}$ & $-{ }^{b}$ \\
8 & $\mathbf{1 9 h}$ & $\left(\mathrm{CH}_{2}\right)_{2}\left(\mathrm{CF}_{2}\right)_{5} \mathrm{CF}_{3}$ & $61^{c}$ \\
9 & $\mathbf{1 9 i}$ & $\left(\mathrm{CH}_{2}\right)_{2}\left(\mathrm{CF}_{2}\right)_{7} \mathrm{CF}_{3}$ & $48^{c}$ \\
10 & $\mathbf{1 9 j}$ & $\left(\mathrm{CH}_{2}\right)_{2} \mathrm{COOC}_{2} \mathrm{H}_{5}$ & $-{ }^{b}$ \\
${ }^{a}$ & Yield from amine. ${ }^{b} \mathrm{Commercially}^{\mathrm{C}}$ \\
\multicolumn{4}{c}{ available. ${ }^{c} \mathrm{Yield} \mathrm{from} \mathrm{iodide.}^{-}$}
\end{tabular}

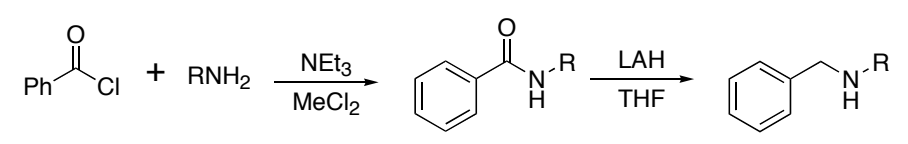

General procedure for the preparation of alkyl benzyl-protected amines from commercially available primary amines based on the synthesis of N-benzyl-Noctylamine (19a).

N-Octylbenzamide. Benzoyl chloride (36.25 g, $258 \mathrm{mmol})$ was dissolved in dichloromethane $(300 \mathrm{~mL})$ and cooled to $0{ }^{\circ} \mathrm{C}$ with an ice bath. A solution of octylamine $(29.75 \mathrm{~g}, 230 \mathrm{mmol})$ and triethylamine $(28.02 \mathrm{~g}, 277 \mathrm{mmol})$ in dichloromethane (100 $\mathrm{mL}$ ) was added over $1 \mathrm{~h}$. The ice bath was removed and the reaction was stirred at ambient temperature overnight. The resulting solution was washed with $10 \% \mathrm{HCl}$, water, saturated aqueous $\mathrm{NaHCO}_{3}$, and brine (100 $\mathrm{mL}$ of each). The organic solution was dried over $\mathrm{MgSO}_{4}$, filtered through Celite, and the solvent was removed by rotary evaporation followed by a high vacuum line to give $\mathrm{N}$-octylbenzamide as a white solid. 
N-Benzyl-N-octylamine (19a). Lithium aluminum hydride (21.82 g, $0.575 \mathrm{~mol})$ was suspended in THF $(300 \mathrm{~mL})$ and cooled to $0{ }^{\circ} \mathrm{C}$ with an ice bath. N-octylbenzamide $(53.67 \mathrm{~g}, 0.230 \mathrm{~mol})$ dissolved in THF $(50 \mathrm{~mL})$ was added at a rate slow enough to prevent excessive foaming. Once the addition was complete, the cooling bath was removed and a reflux condenser was added. The reaction was heated at reflux for $4 \mathrm{~h}$. The reaction was cooled to $0{ }^{\circ} \mathrm{C}$ and the excess $\mathrm{LiAlH}_{4}$ was quenched by sequential dropwise addition of $21.8 \mathrm{~mL}$ DI water, $21.8 \mathrm{~mL} \mathrm{15 \%} \mathrm{NaOH}$ and $65.4 \mathrm{~mL}$ DI water with rapid stirring. The quenched reaction was allowed to stir for $\sim 1 \mathrm{~h}$ after last addition, then the resulting white precipitate was removed by filtration through a pad of Celite. The solvent was removed by rotary evaporation and the resulting yellow oil was purified by vacuum distillation (bp $75-85^{\circ} \mathrm{C} @ 0.7 \mathrm{~mm} \mathrm{Hg}$ ) to yield 19a as a colorless oil (42.92 $\mathrm{g}$, $0.196 \mathrm{~mol}, 85 \%$ yield over two steps). ${ }^{1} \mathrm{H} \mathrm{NMR}\left(\mathrm{CDCl}_{3}\right) \delta \quad 7.21-7.34(\mathrm{~m}, 5 \mathrm{H}), 3.79$ (s, 2H), $2.62(\mathrm{t}, J=7.2 \mathrm{~Hz}, 2 \mathrm{H}), 1.49(\mathrm{~m}, 3 \mathrm{H}), 1.27(\mathrm{~m}, 10 \mathrm{H}), 0.88(\mathrm{t}, J=6.6 \mathrm{~Hz}, 3 \mathrm{H}) .{ }^{13} \mathrm{C}$ $\operatorname{NMR}\left(\mathrm{CDCl}_{3}\right) \delta 128.3,128.1,126.8,54.1,49.5,31.8,30.1,29.5,29.3,27.3,22.6,14.1$. Anal. Calcd for $\mathrm{C}_{15} \mathrm{H}_{25} \mathrm{~N}$ : C, 82.13; H, 11.49; N, 6.39. Found: C, 81.85; H, 11.77; N, 6.45 .

N-Benzyl-N-decylamine (19c). ${ }^{1} \mathrm{H}$ NMR $\left(\mathrm{CDCl}_{3}\right) \delta 7.31(\mathrm{~m}, 5 \mathrm{H}), 3.79(\mathrm{~s}, 2 \mathrm{H}), 2.62$ (t, J $=7.2 \mathrm{~Hz}, 2 \mathrm{H}), 1.51(\mathrm{~m}, 3 \mathrm{H}), 1.25(\mathrm{~m}, 28 \mathrm{H}), 0.88(\mathrm{t}, J=6.6 \mathrm{~Hz}, 3 \mathrm{H})$. Anal. Calcd for $\mathrm{C}_{17} \mathrm{H}_{29} \mathrm{~N}:$ C, 82.52; H, 11.81; N, 5.66. Found: C, 82.44; H, 11.94; N, 5.54.

N-Benzyl-N-hexadecylamine (19d). (mp 33.5-35.1 $\left.{ }^{\circ} \mathrm{C}\right) \quad{ }^{1} \mathrm{H}$ NMR $\left(\mathrm{CDCl}_{3}\right) \delta 7.31(\mathrm{~m}$, $5 \mathrm{H}), 3.79(\mathrm{~s}, 2 \mathrm{H}), 2.62(\mathrm{t}, J=7.5 \mathrm{~Hz}, 2 \mathrm{H}), 1.51(\mathrm{~m}, 3 \mathrm{H}), 1.26(\mathrm{~m}, 14 \mathrm{H}), 0.88(\mathrm{t}, J=6.6$ $\mathrm{Hz}, 3 \mathrm{H})$. Anal. Calcd for $\mathrm{C}_{23} \mathrm{H}_{41} \mathrm{~N}$ : C, 83.31; H, 12.46; N, 4.22. Found: C, 83.38; H, $12.26 ; \mathrm{N}, 4.34$. 
General procedure for the preparation of perfluorinated benzyl-protected amines from commercially available perfluoro-iodides based on the synthesis of N-benzylN-1H,1H,2H,2H-perfluorodecane (19i).

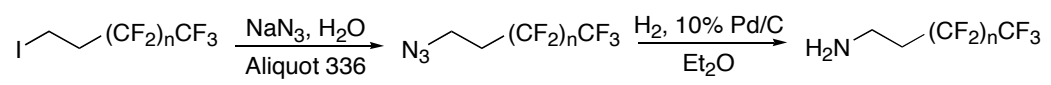

1-Amino-1H,1H,2H,2H-perfluorodecane. Sodium azide (2.60 g, $40 \mathrm{mmol})$ was dissolved in DI water $(18 \mathrm{~mL})$ with $0.4 \mathrm{~g}$ Aliquot 336 in a 50 - $\mathrm{mL}$ single neck round bottom flask and 1-iodo-1H,1H,2H,2H-perfluorodecane (11.49 g, $20 \mathrm{mmol})$ was added. The solution was heated in order to melt the iodide starting material and the reaction mixture was allowed to reflux with rapid stirring overnight. The reaction was allowed to cool to rt and the aqueous solution was removed with a pipet. The azide product was taken up in ether $(50 \mathrm{~mL})$ and decanted away from the remaining aqueous solution into a Parr flask. $10 \% \mathrm{Pd}$ on carbon $(250 \mathrm{mg}$ ) was added and the reaction flask was charged to $50 \mathrm{psi}_{2}$. The reaction was allowed to shake for $1 \mathrm{~h}$, vented to release the produced $\mathrm{N}_{2}$, recharged to $50 \mathrm{psi}_{2}$ and allowed to shake overnight. Catalyst was removed by filtration through Celite and the amine product was concentrated to yellow oil.

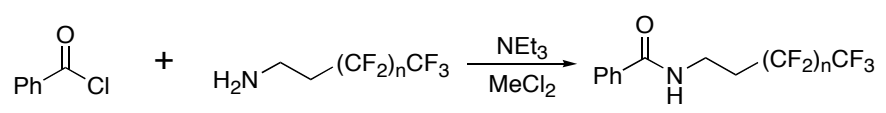

$\mathbf{N}-1 \mathbf{H}, \mathbf{1 H}, 2 \mathrm{H}, 2 \mathrm{H}$-perfluorodecanebenzylamide. Crude amine product and $\mathrm{NEt}_{3}(3.4$ $\mathrm{mL}, 24 \mathrm{mmol})$ were dissolved in freshly distilled $\mathrm{CH}_{2} \mathrm{Cl}_{2}(200 \mathrm{~mL})$ then cooled to $0{ }^{\circ} \mathrm{C}$. Benzoyl chloride $(2.6 \mathrm{~mL}, 22 \mathrm{mmol})$ was added dropwise and the reaction mixture was stirred overnight. The solution was diluted with diethyl ether $(100 \mathrm{~mL})$, washed with saturated aqueous $\mathrm{NaHCO}_{3}(2 \times 125 \mathrm{~mL})$ and brine $(125 \mathrm{~mL})$, dried $\left(\mathrm{MgSO}_{4}\right)$, filtered and concentrated by rotary evaporation to a dark brown oil. This oil was taken up in ethanol, 
stirred with activated charcoal, and filtered to yield a yellow solution. The volume of solvent was reduced to ca. $150 \mathrm{~mL}$ by heating under a directed stream of $\mathrm{N}_{2}$ and recrystallizations/precipitation was effected by adding hot DI water $(\sim 50 \mathrm{~mL})$, then allowing the solution to cool to rt slowly. The benzyl amide product was recovered as a white powder by vacuum filtration and dried overnight at $60{ }^{\circ} \mathrm{C}(9.30 \mathrm{~g}, 16.4 \mathrm{mmol}, 82 \%$ yield over 3 steps).

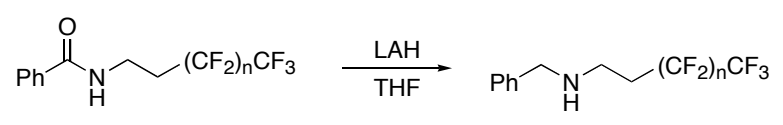

\section{N-Benzyl-N-1H,1H,2H,2H-perfluorodecane $\quad$ (19i). $\quad \mathrm{N}-1 \mathrm{H}, 1 \mathrm{H}, 2 \mathrm{H}, 2 \mathrm{H}-$}

perfluorodecanebenzylamide $(9.30 \mathrm{~g}, 16.4 \mathrm{mmol})$ was dissolved in freshly distilled THF $(300 \mathrm{~mL})$ and cooled to $0{ }^{\circ} \mathrm{C}$. Lithium aluminum hydride $(1.70 \mathrm{~g}, 44.7 \mathrm{mmol}, 2.7 \mathrm{eq})$ was added slowly with rapid stirring (CAUTION: fizz) and the reaction mixture was allowed to reflux overnight. The reaction was then cooled to $0{ }^{\circ} \mathrm{C}$ and quenched by sequential dropwise addition of $1.7 \mathrm{~mL}$ DI $\mathrm{H}_{2} \mathrm{O}, 1.7 \mathrm{~mL} 15 \% \mathrm{NaOH}$, and $5.1 \mathrm{~mL} \mathrm{DI} \mathrm{H}_{2} \mathrm{O}$ and stirred for an additional $30 \mathrm{~min}$. The resulting grey-green slurry was then filtered through Celite and the solution concentrated to a yellow oil which was distilled (110-120 ${ }^{\circ} \mathrm{C} @ 100$ mTorr) to yield $19 \mathbf{i}$ as a colorless oil which solidifies around rt (5.32 g, 9.6 mmol, 59\% yield). 


\section{Synthetic Attempts Towards the Acid-Functionalized Bicyclic Malonamide.}

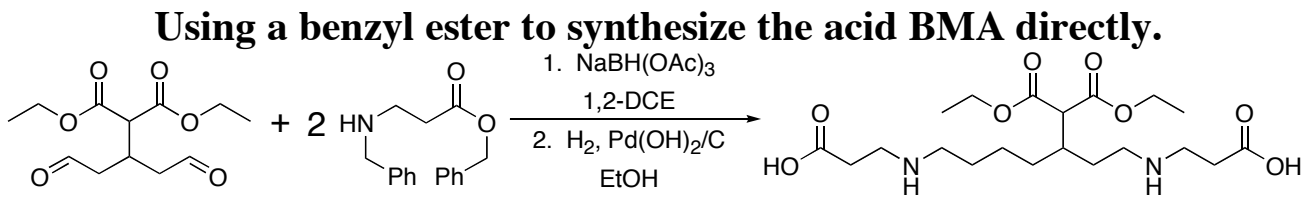

The reductive amination and hydrogenolysis are performed in the same manner as reported in the article and had been successful to the point of achieving an elemental analysis of the acid-functionalized bicyclic malonamide (Anal. Calcd. for $\mathrm{C}_{14} \mathrm{H}_{20} \mathrm{~N}_{2} \mathrm{O}_{6}$ : C, 53.84; H, 6.45; N, 8.97. Found: C, 53.81; H, 6.34; N, 9.19.). However, upon repeating the reaction sequence, no spontaneous lactam formation occurred. The uncyclized intermediate 6 is isolable (it was thoroughly characterized via ${ }^{1} \mathrm{H}$ and ${ }^{13} \mathrm{C} N \mathrm{NR}$, IR, and elemental analysis) and the ${ }^{1} \mathrm{H}$ NMR in $\mathrm{D}_{2} \mathrm{O}$ (shown below) integrates perfectly, though the amine and acid protons are not detectable. (mp 124.5-125.8 $\left.{ }^{\circ} \mathrm{C}\right){ }^{1} \mathrm{H}$ NMR $\left(\mathrm{D}_{2} \mathrm{O}\right) \delta$ $4.25\left(\mathrm{dq}, J_{s}=1.5, J_{l}=7.2 \mathrm{~Hz}, 4 \mathrm{H}\right), 3.77(\mathrm{~d}, J=5.4 \mathrm{~Hz}, 1 \mathrm{H}), 3.23(\mathrm{t}, J=6.6 \mathrm{~Hz}, 4 \mathrm{H}), 3.14$ (t, $J=8.3 \mathrm{~Hz}, 4 \mathrm{H}), 2.57(\mathrm{t}, J=6.6 \mathrm{~Hz}, 4 \mathrm{H}), 2.34(\mathrm{q}, J=6.1 \mathrm{~Hz}, 1 \mathrm{H}), 1.84(\mathrm{~m}, 4 \mathrm{H}), 1.27$ (t, $J=6.9 \mathrm{~Hz}, 6 \mathrm{H}) .{ }^{13} \mathrm{C} \mathrm{NMR}\left(\mathrm{CDCl}_{3}\right) \delta 178.1,170.1,63.2,45.1,44.5,33.0,32.6,27.7$, 13.3. Anal. Calcd. for $\mathrm{C}_{18} \mathrm{H}_{32} \mathrm{~N}_{2} \mathrm{O}_{8}$ : C, 53.45; H, 7.97; N, 6.93. Found: C, 53.20; H, 7.68; N, 6.94 . 


\section{${ }^{1}$ H NMR of ester-amine intermediate 6.}

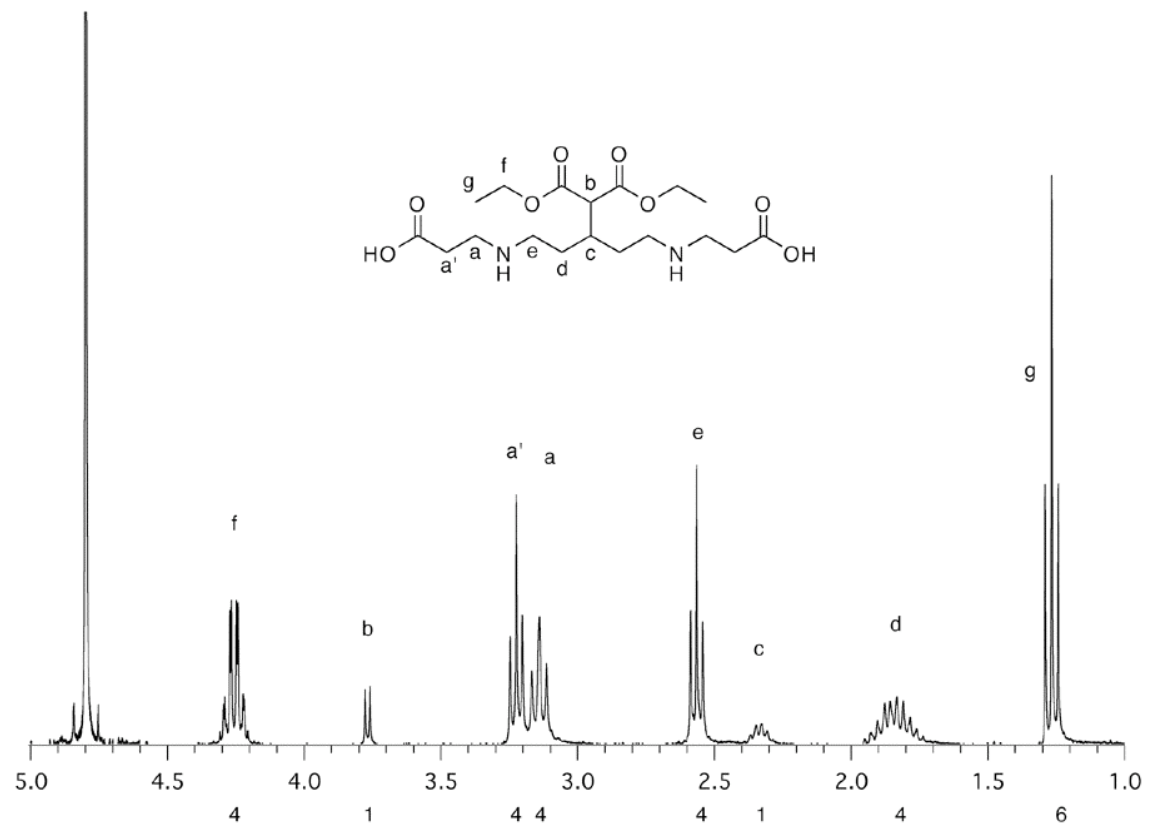

However, unlike every other derivative synthesized, this intermediate resists proceeding to the fully ring-closed product. Though the starting reaction solution was clear and colorless, after $18 \mathrm{~h}$ refluxing in water a small amount of gray precipitate was noted in the flask. The reaction was decanted away from the char and concentrated to a yellow oil. The proton NMR showed a mixture of starting material and product. Refluxing overnight in ethanol is usually sufficient to drive the lactam-formation to completion; since $18 \mathrm{~h}$ in a higher boiling solvent lead to perhaps $50 \%$ conversion and some decomposition (char), an alternative route was investigated. 


\section{Using the ethyl ester BMA as the acid BMA precursor.}

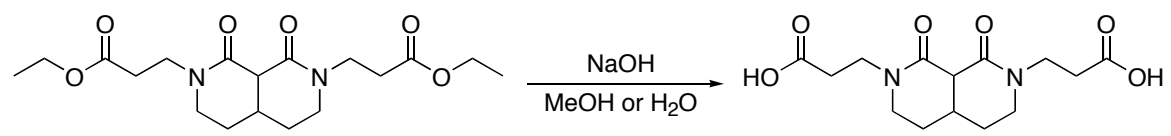

Ester $\mathbf{1} \mathbf{j}$ is easily obtained in large quantities and good yields, so hydrolysis of the ester groups was attempted. The methods are described below. The hydrolysis in methanol proceeded in excellent yield (94\%) and the ${ }^{1} \mathrm{H}$ and ${ }^{13} \mathrm{C}$ NMR were clean, the chemical shifts made sense and they integrated correctly. There was, however, one extra peak in both spectra $\left({ }^{1} \mathrm{H}\right.$ and ${ }^{13} \mathrm{C}$ NMR) that indicated a methyl ester (the singlet in the ${ }^{1} \mathrm{H}$ NMR integrated to $6 \mathrm{H}$ and the chemical shifts were appropriate). Thinking that perhaps a transesterification was more favorable than hydrolysis in this molecule, the reaction was repeated in $\mathrm{DI} \mathrm{H}_{2} \mathrm{O}$. The yield was slightly lower (75\%), but the spectra were identical and still indicated a methyl ester. Addition of $\mathrm{D}_{2} \mathrm{O}$ to the $\mathrm{CDCl}_{3} \mathrm{NMR}$ sample would have decreased the singlet intensity if it were due to waters of hydration, but no change was noted. All spectroscopy indicates the methyl ester, but the reaction conditions do not support its formation and the elemental analysis for the methyl ester is slightly out of range for carbon.

3,9-Diaza-3,9-bis(2-methoxycarbonylethyl)bicyclo[4.4.0]decane-2,10-dione. Ester $\mathbf{1 j}(0.515 \mathrm{~g}, 1.4 \mathrm{mmol})$ was dissolved in methanol $(25 \mathrm{~mL})$ and solid $\mathrm{NaOH}(0.169 \mathrm{~g}, 4.2$ $\mathrm{mmol})$ and water $(0.072 \mathrm{~g}, 4.0 \mathrm{mmol})$ were added. The mixture was allowed to stir $1 \mathrm{~h}$, then was acidified to $\mathrm{pH} \sim 3$ with $10 \% \mathrm{HCl}$ and extracted with $\mathrm{CHCl}_{3}(5 \times 10 \mathrm{~mL})$ in the presence of solid $\mathrm{NaCl}$. The organics were washed with satd. $\mathrm{NaHCO}_{3}$ (white ppt was kept separate from the product) and dried over $\mathrm{Na}_{2} \mathrm{SO}_{4}$. Concentration by rotary evaporation yielded a pale yellow oil $(0.45 \mathrm{~g}, 94 \%$ yield $) .{ }^{1} \mathrm{H} \mathrm{NMR}\left(\mathrm{CDCl}_{3}\right) \delta 3.656$ (s, $6 \mathrm{H}), 3.61\left(\mathrm{dt}, J_{S}=4.5, J_{L}=6.9 \mathrm{~Hz}, 4 \mathrm{H}\right), 3.37\left(\mathrm{dd}, J_{S}=5.4, J_{L}=7.5 \mathrm{~Hz}, 4 \mathrm{H}\right), 3.24(\mathrm{~d}, J=$ 
$6.0 \mathrm{~Hz}, 1 \mathrm{H}), 2.63\left(\mathrm{dt}, J_{S}=1.5, J_{L}=6.8 \mathrm{~Hz}, 4 \mathrm{H}\right), 2.43(\mathrm{~m}, 1 \mathrm{H}), 1.94\left(\mathrm{dq}, J_{S}=5.4, J_{L}=\right.$ $13.5 \mathrm{~Hz}, 2 \mathrm{H}), 1.66\left(\mathrm{dq}, J_{S}=7.5, J_{L}=21.6 \mathrm{~Hz}, 2 \mathrm{H}\right) .{ }^{13} \mathrm{C} \mathrm{NMR}\left(\mathrm{CDCl}_{3}\right) \delta \quad 172.6,166.4$, 51.7, 50.2, 46.6, 43.9, 32.2, 30.3, 27.0. Anal. Calcd. for $\mathrm{C}_{16} \mathrm{H}_{24} \mathrm{~N}_{2} \mathrm{O}_{6}$ :

3,9-Diaza-3,9-bis(2-carboxyethyl)bicyclo[4.4.0]decane-2,10-dione. Ester 1j (0.348 $\mathrm{g}, 0.9 \mathrm{mmol})$ and $\mathrm{NaOH}(0.091 \mathrm{~g}, 2.3 \mathrm{mmol})$ were dissolved in $\mathrm{DI}_{2} \mathrm{O}(15 \mathrm{~mL})$ and allowed to stir $1 \mathrm{~h}$. The $\mathrm{pH}$ of the reaction mixture was lowered to $\sim 6$ with $10 \% \mathrm{HCl}$ and extracted with $\mathrm{CHCl}_{3}(5 \times 10 \mathrm{~mL})$. The combined organics were dried over $\mathrm{Na}_{2} \mathrm{SO}_{4}$, filtered, and concentrated to a white powder $(0.210 \mathrm{~g}, 75 \%$ yield $) .{ }^{1} \mathrm{H}$ NMR $\left(\mathrm{CDCl}_{3}\right) \delta$ $3.61\left(\mathrm{dt}, J_{S}=4.5, J_{L}=6.6 \mathrm{~Hz}, 4 \mathrm{H}\right), 3.38\left(\mathrm{dd}, J_{S}=5.4, J_{L}=7.2 \mathrm{~Hz}, 4 \mathrm{H}\right), 3.26(\mathrm{~d}, J=6.3$ $\mathrm{Hz}, 1 \mathrm{H}), 2.65\left(\mathrm{dt}, J_{S}=1.8, J_{L}=6.8 \mathrm{~Hz}, 4 \mathrm{H}\right), 2.44(\mathrm{~m}, 1 \mathrm{H}), 1.95\left(\mathrm{dq}, J_{S}=5.1, J_{L}=14.1\right.$ $\mathrm{Hz}, 2 \mathrm{H}), 1.66\left(\mathrm{dq}, J_{S}=7.8, J_{L}=14.1 \mathrm{~Hz}, 2 \mathrm{H}\right) .{ }^{13} \mathrm{C} \mathrm{NMR}\left(\mathrm{CDCl}_{3}\right) \delta 172.6,166.4,51.7$, 50.2, 46.6, 43.9, 32.2, 30.3, 27.0. Anal. Calcd. for $\mathrm{C}_{14} \mathrm{H}_{20} \mathrm{~N}_{2} \mathrm{O}_{6}$ : C, 53.84; H, 6.45; N, 8.97. Found: C, 53.81; H, 6.34; N, 9.19. 
Spectroscopic Analysis of the BMA Structure. The infrared spectrum of $\mathbf{1 b}$ shows a strong absorption at $1651 \mathrm{~cm}^{-1}$ corresponding to the amide carbonyl stretch. In addition there is a broad absorption centered at $3439 \mathrm{~cm}^{-1}$ suggesting the diamide has some enol character although the enol form is not apparent in the ${ }^{1} \mathrm{H}$ NMR spectrum.

The ${ }^{1} \mathrm{H}$ NMR spectrum shows that the free ligand exists as a single isomer, at least within the detection limits of NMR spectroscopy. There is only one singlet for the amide methyl groups (Chart 2 a) and the amide methylenes (Chart 2 e) appear further downfield as an apparent doublet of doublets. The methyne proton between the carbonyls (Chart 2 b) is a doublet, which is obscured by the amide methylenes in deuterated chloroform. [In deuterium oxide, some of the resonances shift downfield and the methyne (b) doublet at $3.38 \mathrm{ppm}$ can easily be differentiated from the amide methylenes (e) at $3.45 \mathrm{ppm}$. The most distinctive ${ }^{1} \mathrm{H}$ NMR signals for the BMA ligand class correspond to methyne $\mathrm{c}$ and methylenes d. Methyne c is a ddddd (app. qt) at ca. $2.4 \mathrm{ppm}$, the $J$ values of which can only be determined by deuterium exchange of acidic proton b. Methylenes $d$ always result in a pair of resonances. These peaks are both doublets of quartets: one is clearly a doublet of quartets at ca. $2.0 \mathrm{ppm}\left(J_{S}=5.4 \mathrm{~Hz}, J_{L}=13.8 \mathrm{~Hz}\right)$ and the other appears as a five to six line multiplet (neither a pentet nor a sextet) at ca. $1.7 \mathrm{ppm}\left(J_{S}=7.8 \mathrm{~Hz}, J_{L}=\right.$ 13.5 Hz). These ring protons appear much the same in the ${ }^{1} \mathrm{H}$ NMR of every derivative of $\mathbf{1}$, except when they are obscured by new resonances. Furthermore, the $J_{3}$ coupling constant of the protons at the ring junction is $5.6 \mathrm{~Hz}$, which suggests that 1a (and thus all other derivatives, as these peaks do not change shape) is the cis stereoisomer. The coupling of these protons in the trans stereoisomer would be expected to have a much larger coupling constant (ca. 10-15 Hz). Proton b slowly exchanges with $\mathrm{D}_{2} \mathrm{O}$ over a 
period of 14 days. It is interesting that while the proton is completely exchanged over this period there is no evidence of epimerization of the ring system. The ${ }^{1} \mathrm{H}$ NMR spectrum still exhibits a single isomer.

Chart S1. Bicyclic malonamide proton assignments for NMR.

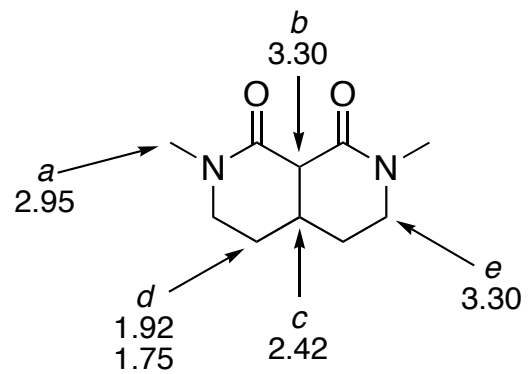

The various derivatives synthesized open up many different avenues of study with this class of ligand. The methyl-substituted $\mathbf{1 b}$ is water soluble, allowing for single-phase binding studies (and comparison to analogous acyclic malonamides showing great enhancement in binding). Bicyclic $\mathbf{1 b}$ also crystallizes alone and as lanthanide complexes, allowing for direct comparison of the free and bound ligand structure. ${ }^{5,18,20}$ The longer alkyl chains are organics-soluble; the octyl-substituted 1a has been used in extraction studies that have demonstrated a tremendous enhancement over the analogous acyclic malonamide ligands. ${ }^{6}$ However, purification of $\mathbf{1 a}$ was difficult previous to the discovery of the uranyl precipitation method; recrystallization was the most appealing method, but a room temperature melting point made this more challenging. Longer chain derivatives were synthesized in anticipation of similar solubility and simpler purifications. Decyl 1c and hexadecyl 1d were found to have higher melting points (47 and $76{ }^{\circ} \mathrm{C}$, respectively), making purification by recrystallization much easier. The addition of perfluorinated sidechains (1/h and $\mathbf{1 i})$ hinder the organic- and water-solubility of the ligand, but dramatically enhance solubility in supercritical fluid $\mathrm{CO}_{2}$. Hydroxyls 
(1f and $\mathbf{1 g}$ ) and ester (1j) offer potential for further chelation, incorporation into

functional materials or further functionalization which could not survive the reaction conditions (e.g. alkenes and thiols).

\section{${ }^{1} \mathrm{H}$ NMR Spectra of $1 \mathrm{~b}$ in $\mathrm{CDCl}_{3}$ and $\mathrm{D}_{2} \mathrm{O}$.}

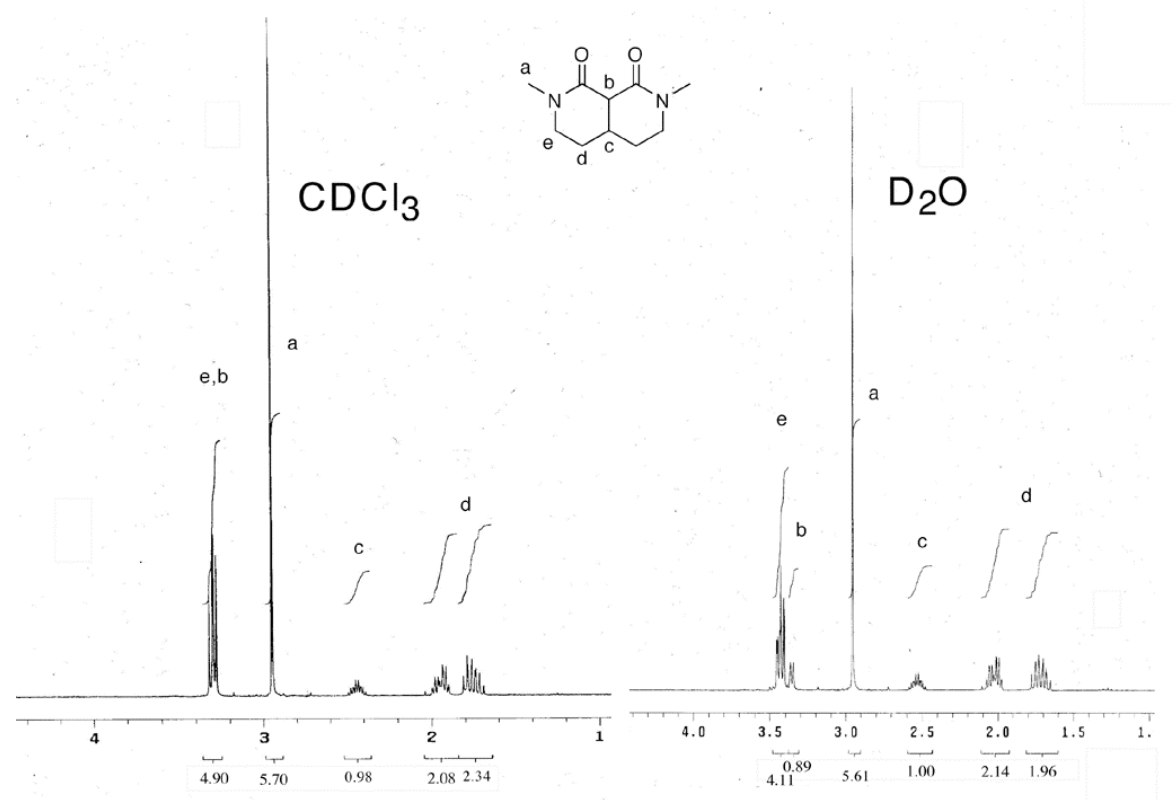


${ }^{1}$ H NMR of [acid/methyl ester] BMA product.

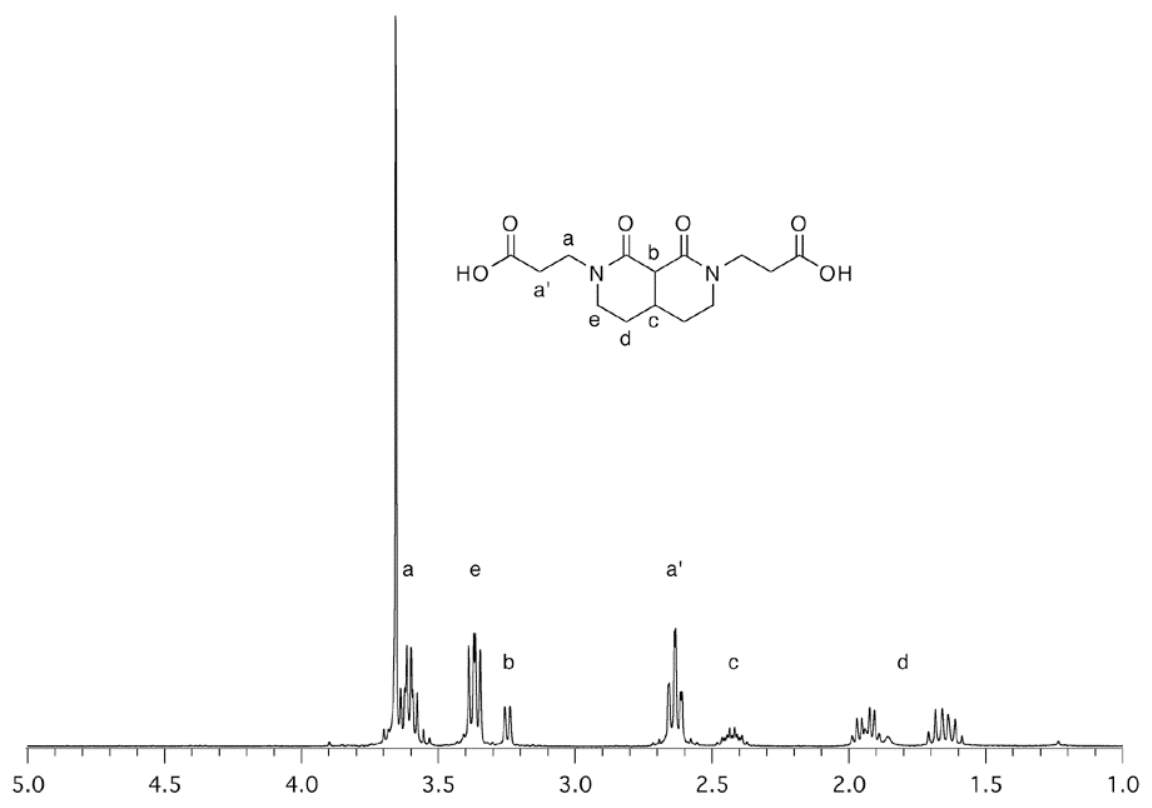

Resolution of methyne $\mathrm{c}$ through dueteration of the BMA.

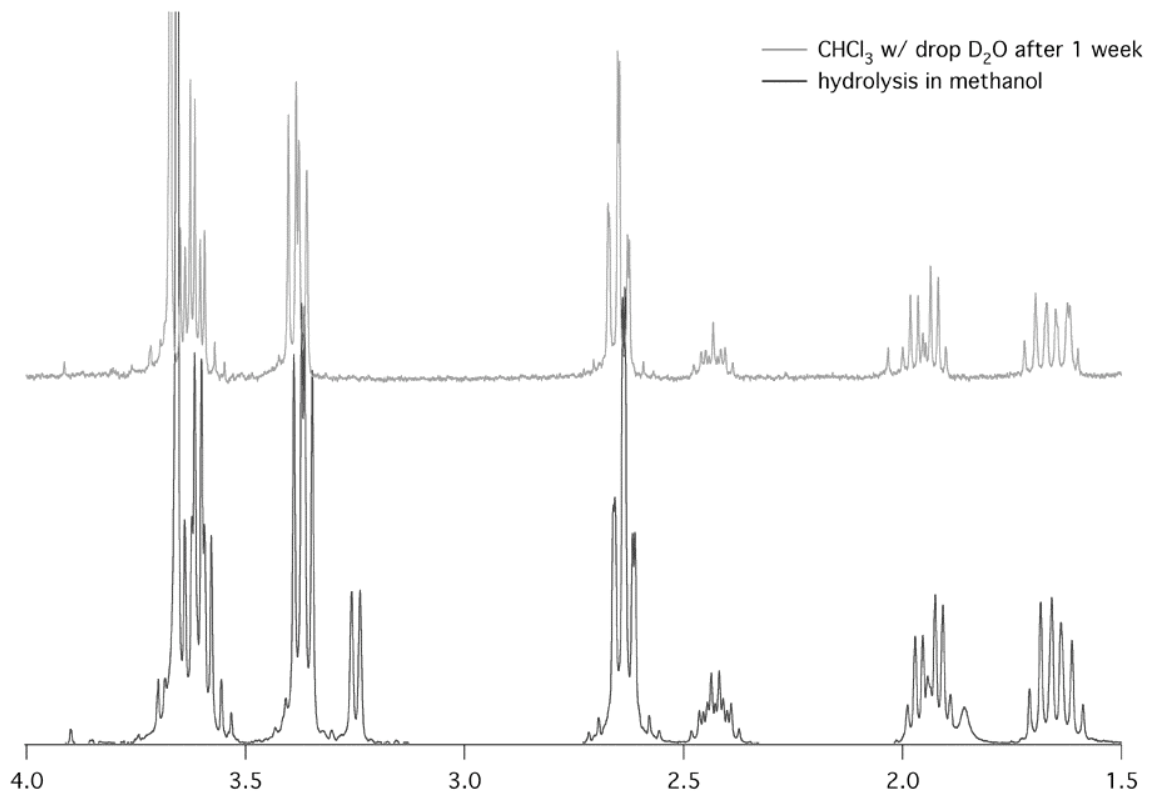


Expansion of the resonance due to the methyne c proton.

The final splitting is equivalent to the splitting of methyne $b$ (doublet at $3.3 \mathrm{ppm}$, vide supra).

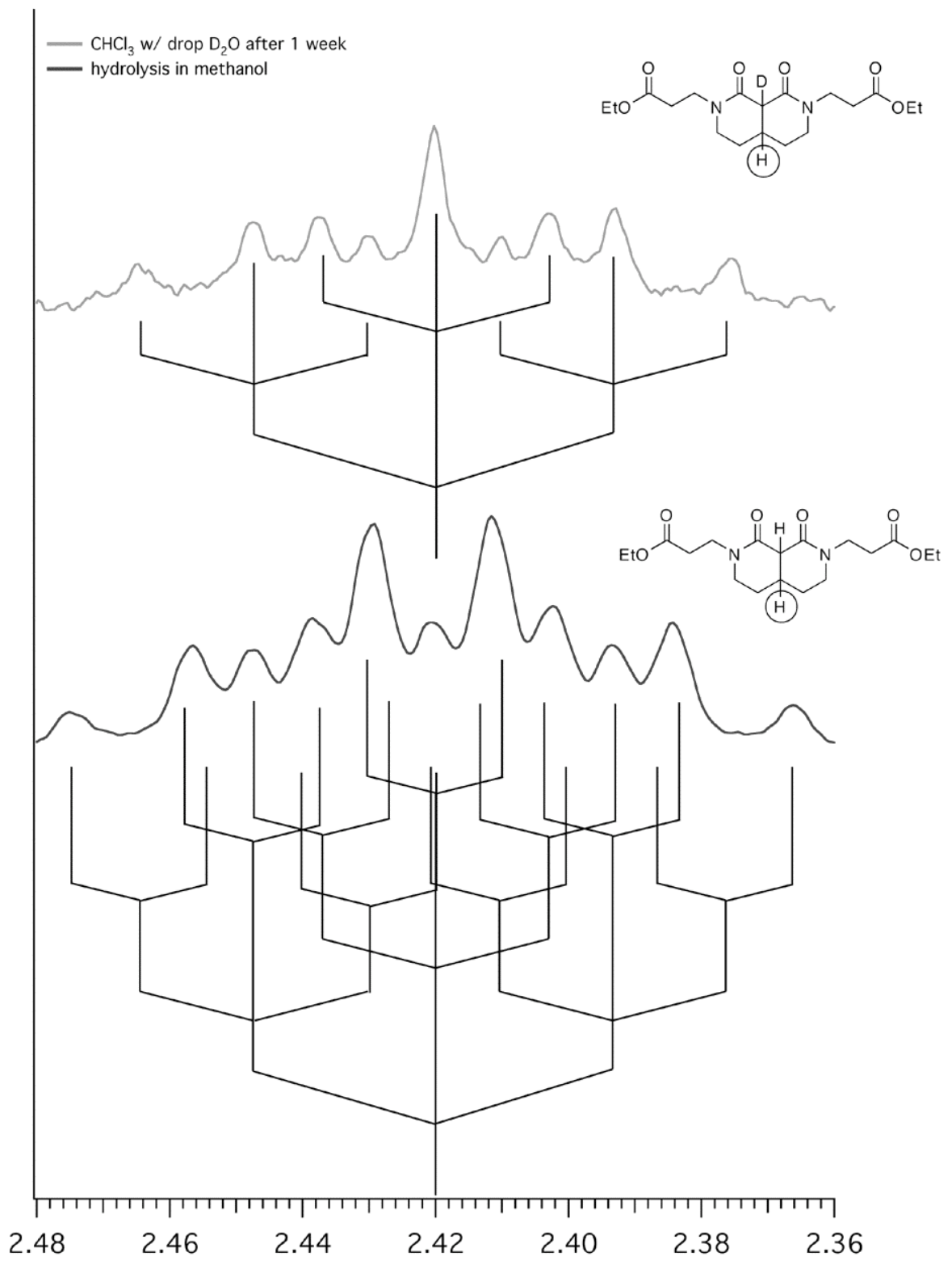


${ }^{1} \mathrm{H}$ NMR spectra of $1 \mathrm{e}, 1 \mathrm{1}, \mathrm{g}$ for purity
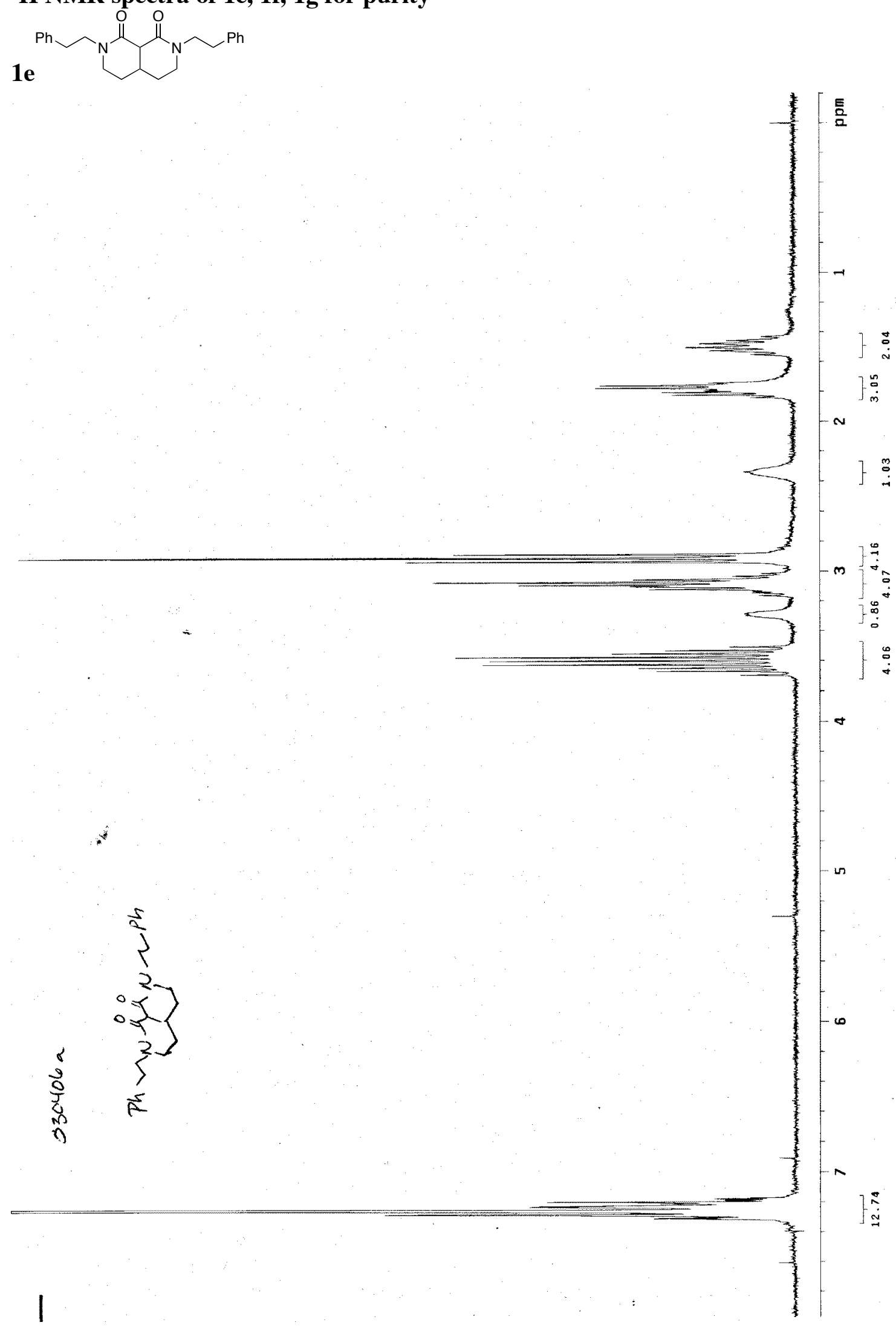
1f in $\mathrm{CDCl}_{3}$

*
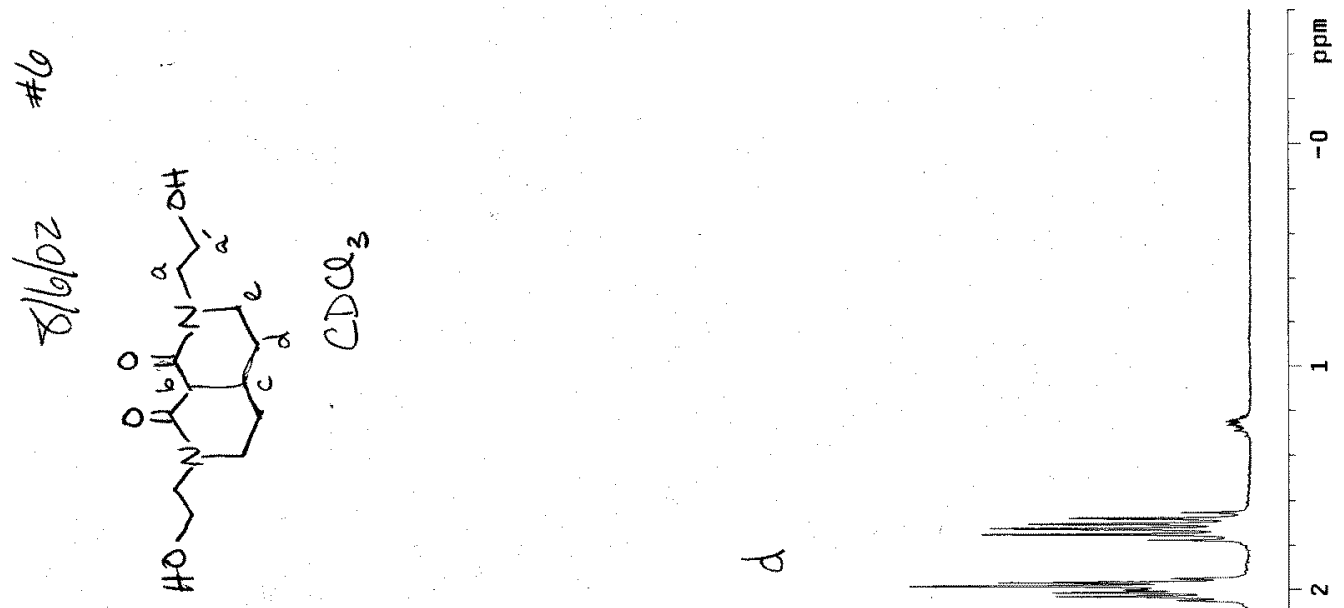

$J$

2

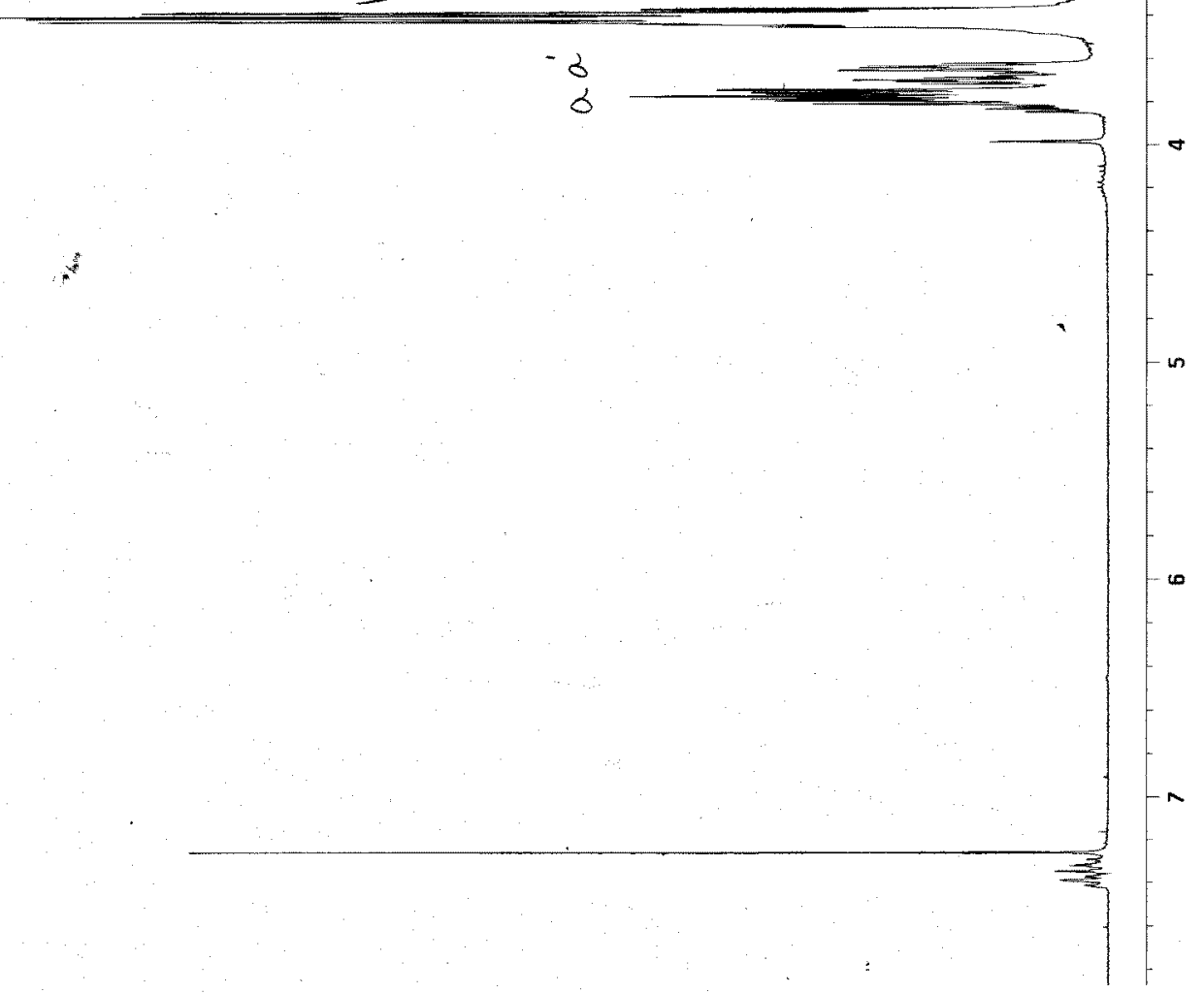



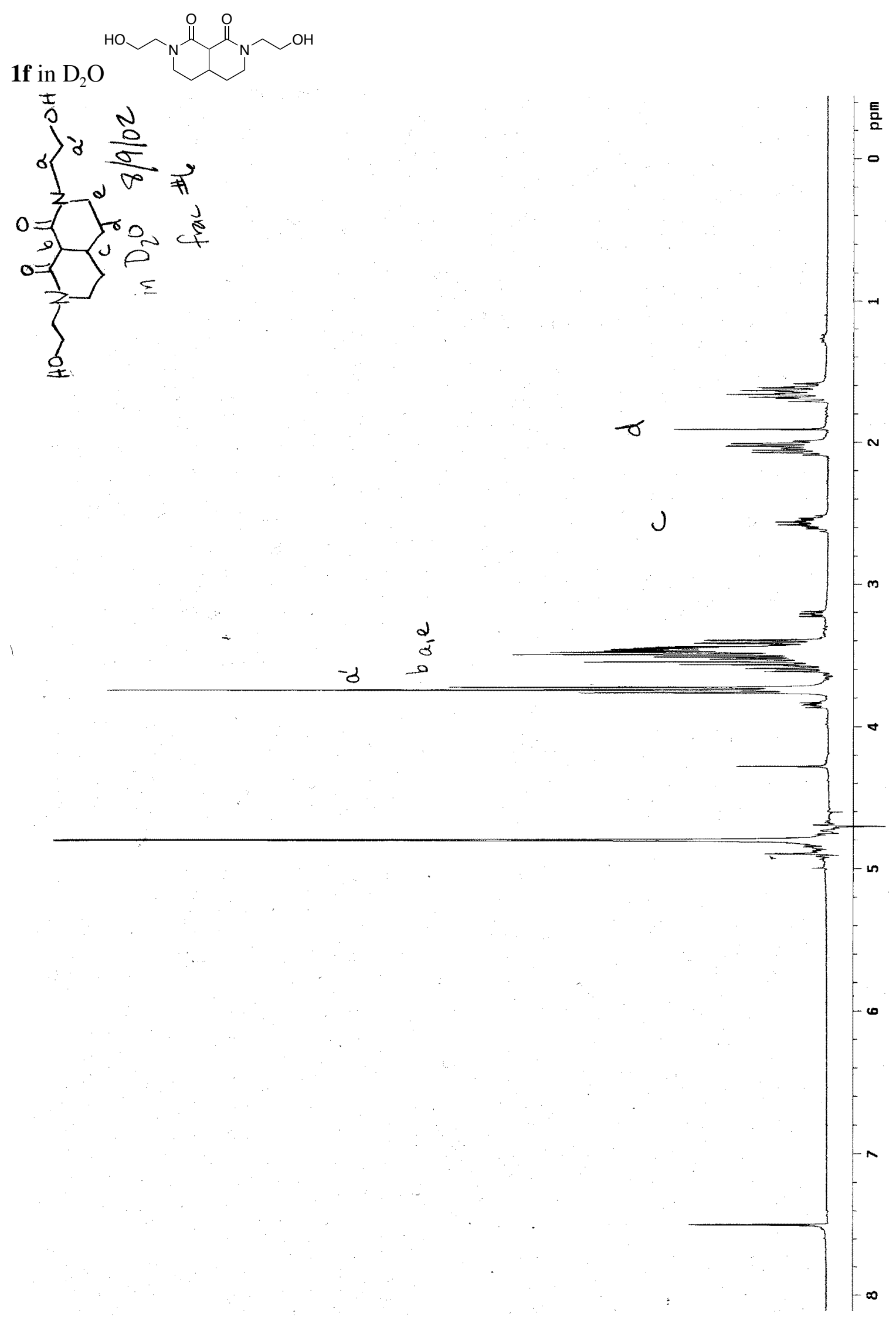

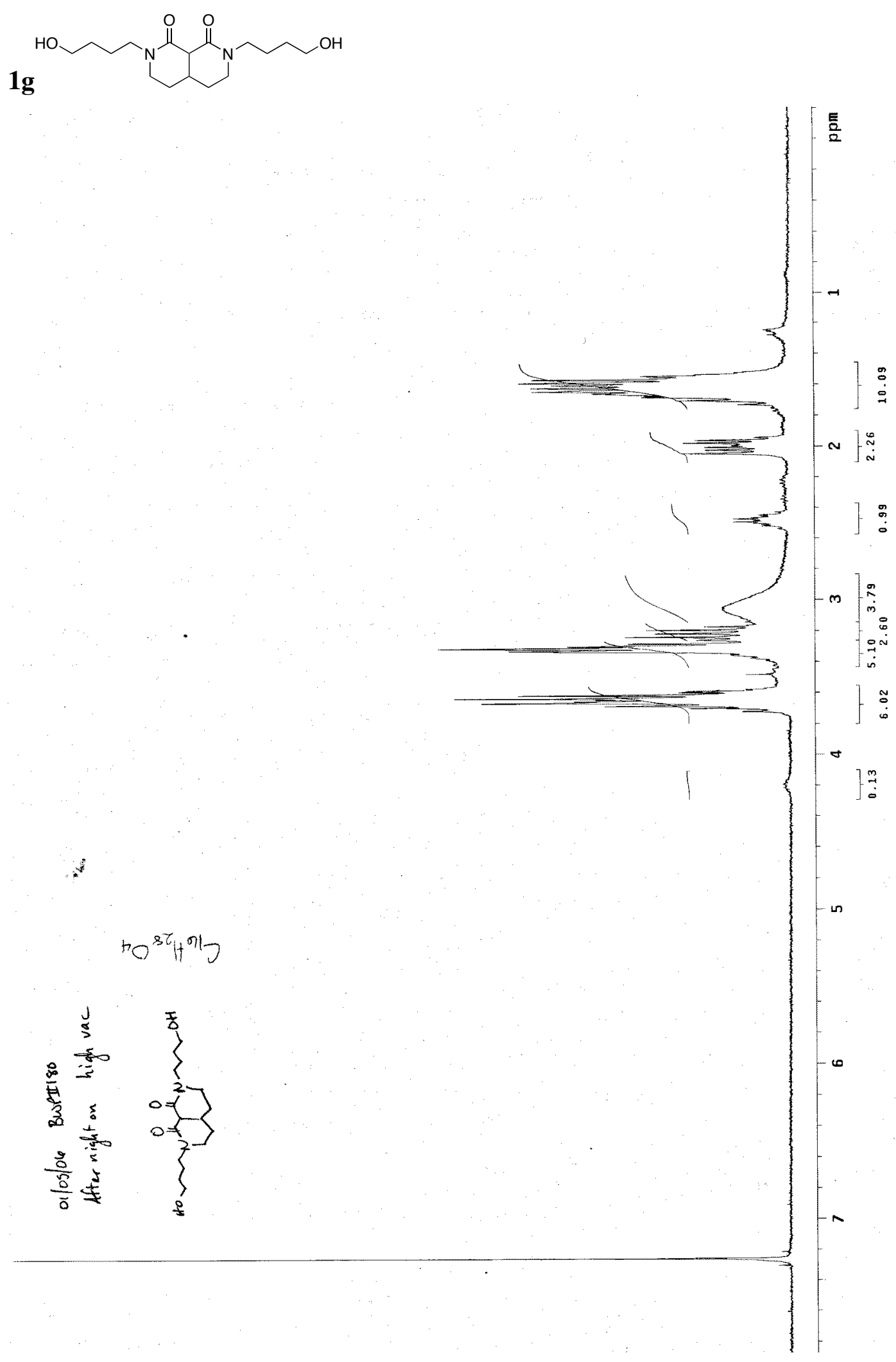